\title{
Solving Multi-Resource Constrained Project Scheduling Problem using Ant Colony Optimization
}

\author{
Hsiang-Hsi Huang ${ }^{1}$, Ching-Hsu Huang ${ }^{2}$, and Wen Pei ${ }^{3}$ \\ ${ }^{1}$ Professor and Vice Dean, Department of Industrial Management, National Pingtung University of Science and \\ Technology, 1, Xuefu Rd., Neipu Township, Pingtung County 91201, Taiwan (R.O.C.), E-mail: \\ hhuang@mail.npust.edu.tw (Corresponding author). \\ ${ }^{2}$ Associate Professor, Department of Hotel and Restaurant Management, National Pingtung University of Science and \\ Technology, 1, Xuefu Rd., Neipu Township, Pingtung County 91201, Taiwan (R.O.C.), E-mail: \\ chinghsu@mail.npust.edu.tw \\ ${ }^{3}$ Associate Professor, Department of Business Administration, Chung Hua University, 707, Sec.2, WuFu Rd., Hsinchu \\ 30012, Taiwan (R.O.C.), E-mail: wpei@chu.edu.tw
}

\author{
Project and Production Management \\ Received January 27, 2014; received revisions August 19, 2014; September 9, 2014; accepted September 19, 2014 \\ Available online November 11, 2014
}

\begin{abstract}
This paper applied Ant Colony Optimization (ACO) to develop a resource constraints scheduling model to achieve the resource allocation optimization and the shortest completion time of a project under resource constraints and the activities precedence requirement for projects. Resource leveling is also discussed and has to be achieved under the resource allocation optimization in this research. Testing cases and examples adopted from the international test bank were studied for verifying the effectiveness of the proposed model. The results showed that the solutions of different cases all have a better performance within a reasonable time. These can be obtained through ACO algorithm under the same constrained conditions. A program was written for the proposed model that is able to automatically produce the project resource requirement figure after the project duration is solved.
\end{abstract}

Keywords: Multi-resource constrained project scheduling, make span, ant colony optimization, resource leveling.

\section{Introduction}

With current fast developed technologies and global competition, to quick respond customers' demand and requirement, project management becomes a critical issue for companies and enterprises. Efficient project management is also treated as an effective factor for promoting companies' competitiveness. In practical, one of the major missions for project managers is to plan well the project resources requirement and activity schedules to achieve the goal of due date on time and to minimize project tardiness. Another concerning for companies is the resources allocation and leveling problem. The goal of resource leveling is to reduce the resource requirement fluctuation which always bothers project manager and management. Most current researches seem to focus on the single-mode resource constrained project scheduling problem (SRCPSP). However, in reality, it is rare for only single-mode projects, most managers have to perform different types of projects at the same period of time (Alcaraz et al., 2003; Bell et al., 1991; Valls et al., 2005; Liu and Hongwei, 2006). To approach the reality as possible is the reason that this research includes resource leveling into resource constrained project scheduling problem. All the above can be the project scheduling problems (PSP) which are to best distribute all tangible and intangible resources within limited time. In order to gain the leading position among competitors and obtain the highest enterprise's profit, companies are even more focusing on project quality by pursuing the effective project planning and control to reduce the cost of performing projects. It is worth noticing that project scheduling problem is originally a complicated composing problem. Many researchers tend to apply different algorithms, e.g. simulated annealing method and genetic algorithm, to solve project scheduling problem. In order to deal with multi-resource project problem under limited resources, this research intends to solve the resource allocation and resource leveling problem based on the ant colony optimization. Our intention also includes employing computer programming to process the multi-resource with resource leveling mechanism automatically.

\section{Literature Review}

Both the essential project management techniques, Critical Path Method (CPM) and Program Evaluation and Review Technique (PERT), were developed in 1960. These two techniques are mainly related to time control (Nguyen and Chua, 2014). For project planning and control, resources usage and allocation must be included. Kelly (1963) had 
discussed the Resource Constrained Project Scheduling Problem (RCPSP) and attracted researchers' interests afterwards. In 1990, Boctor's solution for RCPSP mainly emphasized that all the starting times for activities are affected by the predecessor activities' lasting durations and resources required. Therefore, when each one resource requirement is limited and activities have to follow sequencing relationship of a project to achieve certain management objective, one call this problem as resource constrained project scheduling problem. This means that along with time, one allocates one or multi-types of resources to project activities to achieve the expected goal. These kinds of problems usually have assumptions and characteristics as the followings: 1. Among all activities there exist sequencing relationship, the successor activities cannot be started, if its precedent activity is not finished; 2 . Quantities of resources requirement are restricted, resource quantities cannot be temporary increased or reduced. All activities are non-preemptive, which means that once starting an activity, it cannot be terminated; 3. In RCPSP, mode problem represents all the resources quantities and durations are according to the selected mode and all of them are fixed and known; 4. All the resources requirement and availability durations are integers and cannot be divided up. Here, we catch the main characteristics to form the basic assumptions.

\subsection{Resource Leveling}

Resource leveling problem is that under restricted project duration, management attempts to move resources to reduce the peak requirement or resource idle phenomena within flexible times. For such a purpose, one has to rearrange activities within slack time to achieve the resources' usage averaged or evenly. Resource leveling problem is also a combination problem which the complexities growth, the scale of the problem increased. There were researchers including Son and Skiboniewski (1999) and Hiyassat (2000 and 2001), used minimum moment method to solve resource leveling problem.

A new development of resource leveling was discussed by Huang et al. (2011). This new development (Huang et al., 2011) provided a different approach for dealing the resource leveling problem. They presented a decision mechanism and strategy model for which is based on the so call resource leveling rate (RLr). The smaller the leveling rate, the more resources' usage of a project is leveled. This also reveals that the resources capacities are well utilized and work loadings for activities are leveled. The multiresource leveling model will then help project managers and management to control and manipulate the implementation and usage of different types of resources for better project scheduling.

For the traditional way of resource leveling technique, the activities with higher usage of resources will be smoothed and moved to those activities with lower usage of resources, as Fig. 1. (a) shows. The attempt of the moves is to level the usages of activities smoothly. However, in that paper, a totally new different way of smoothing direction was provided which is from the maximum resource required to compress the grey area as the Fig. 1. (b) shows. The mathematic model of resource leveling rate (RLr) is basically the difference between daily resource limitation and daily actual resource requirement. For the goal function value of the resource leveling rate is the smaller the better. The smaller for the difference value, the smoother the resource loading. Nevertheless, due to limited resource quantities, the reducing of resource leveling rate is not unlimited; after certain value, the make-span of the project will then have to be extended.

\subsection{Methods for Resource Constrained Scheduling Problem}

Researches of resource constrained scheduling problem focus mainly on two different aspects, i.e. mathematic model and heuristic model. Solutions can be also belongs to two categories: the optimization approaches and heuristic approaches. The optimization approaches, e.g. the 0-1 integer programming was proposed early by Wiest (1967). Branch and Bound method was applied into resource constrained scheduling problem by MuellerMerbach (1967). In this research, one project has several types of resources required and only one type of resource is allowed to be used for an activity. After Mueller-Merbach' research, Hartmann, Sprecher, and Drexl (1998 and 2001) applied Branch and Bound method to solve the multi-mode resource-constrained project scheduling (MM-RCPSP) problems. In 1975, Davis and Patterson also applied both linear programming and dynamic programming to search for the optimal solution. The optimization method though can guarantee to obtain the best solution; however, it usually is limited in a small scale scheduling problem. When numbers of activities are very large, it cannot then get the optimal solution.

The effect of finding an optimal solution is usually limited by the number of activities. To promote the efficiency of searching the optimal solution, the near optimal methods are then developed nowadays and the heuristic model is one of them. In 1963, Kelley was the first to develop the heuristic model. The model includes Serial Generation Scheduling Scheme (SSGS) and Parallel Generation Scheduling Scheme (PSGS). SSGS method first creates a priority sequence table based on a certain priority rule. According to the priority sequence table, activity is scheduled one by one and as early as possible without violating activity precedent relationship and resource restriction. Parallel Generation Scheduling Scheme instead schedules activities without priority sequence table. PSGS schedules activities according to starting time of activities. The major drawback of SSGS method is lacking of dynamic characteristic which the priority of activities are predetermined at the very beginning. This research, therefore, applies the Parallel Generation Scheduling Scheme as the primary scheduling first.

Other than above methods, heuristic models include Genetic Algorithms (GA), Simulated Annealing (SA), and Ant Colony Optimization (ACO), etc. The major advantage of these heuristic models is that can fast find the near optimal solution to save mass computational time and costs which benefits fACor management. This research will then apply the Ant Colony Optimization method to best search for solution.

In this research, there are some limitations remained which include that the activity duration is fixed, instead of considering the probability durations, and non-recoverable resources are not included in this research. When multimode resource constrained project scheduling problem (MM-RCPSP) contains more than two types of resources, difficulty of obtaining feasible solutions is NP-complete, not to mention to find the optimal solution. 


\section{Ant Colony Optimization and Modeling}

In 1997, Dorigo observed the ants' group cooperation behaviors for finding foods and developed the Ant algorithm to deal with the optimization problems. The primary different characteristics between real ants and artificial ants are listed in the following Table 1. In order to obtain the global optimal, two artificial ant behaviors have to be implemented, one is the development and the other one is exploration. To develop is to improve current solution based on the present existing best routing and searching along this route. However, if one search only on this route and cannot try on other routes, the result could be trapped into the local optimal solution. To explore is to search routes other than current best path and let artificial ants have more chances to obtain global optimal solution. In order to obtain the most effectiveness result, it is critical to make those two mechanisms to operate in coordination when designing the ant system.

\subsection{Research Assumptions and Symbols}

\subsubsection{Research Assumptions}

1. Every project is composed by different activities, and all durations and resources needed are known.

2. Each one activity is now allowed to be separated, once started the activity cannot be terminated.

3. Each resource is the recoverable resource.

4. A resource is released and available after its serving activity is completed.

5. All resources and types of resources needed for each one activity are known and cannot be separated.

6. The sequencing relationship among activities is known. The subsequent activity cannot be started, if its precedent activity is not finished. When any activity is performing, resources requirement are maintained at a fix level, which indicates that resource quantities cannot be temporary increased or reduced.

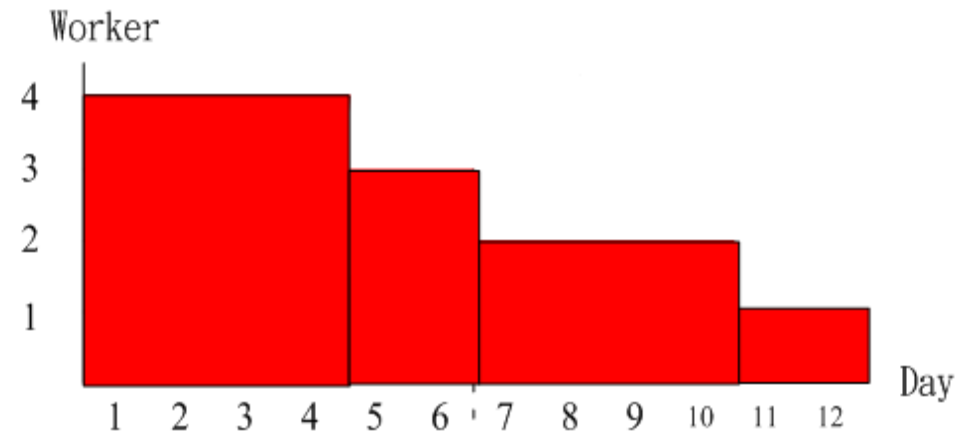

(a) Move the red area into smoother situation

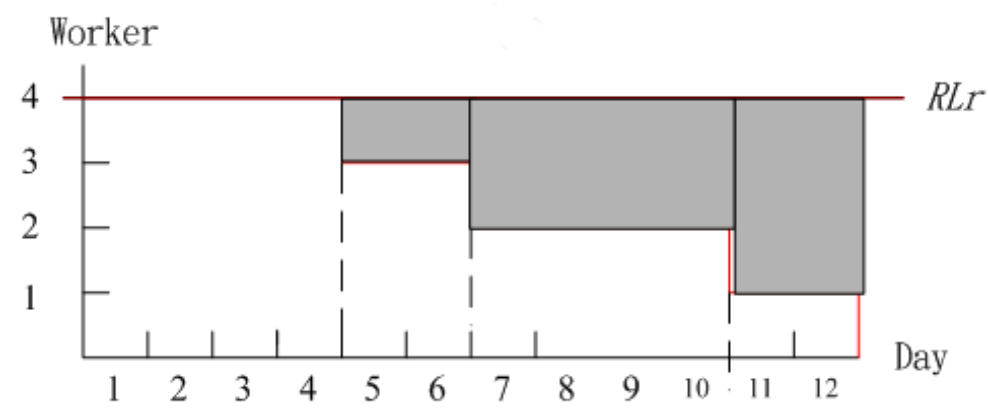

(b) Reduce the grey area by compressing the maximum required for achieving leveling situation

Fig. 1. Different ways of smoothing and leveling

Table 1. The primary different characteristics between real ants and artificial ants

\begin{tabular}{ccc}
\hline Type of ant & Real Ant & Artificial Ant \\
\hline Exist memory ability & No & Yes \\
With vision ability & No & Yes \\
Pheromone renewal & Continuous time renewed & Discrete time renewed \\
Ant movement & Continuous time movement & Discrete time movement \\
\hline
\end{tabular}




\subsubsection{Definition of Symbols}

All the related variables and symbols are defined and listed as follows:

$j=$ number of operations, where $j=1,2,3, \cdots, J$

$t=$ scheduling time point, where $t=1,2,3, \cdots, T$

$T=$ the planned completion time of project

$m=$ executing mode number

$\rho=$ recoverable resource

$k=$ type of resource

$d_{j}=$ the needed lasting time for activity $j$, where $d_{j} \geqq 0$

$r_{j m k}^{\rho}=$ the required quantity of $k$ type of recoverable resource, when activity $j$ is performing $m$ mode

$R_{K}^{\rho}=k$ type of recoverable resource

$E S_{j}=$ the earliest start time of activity $j$

$L F_{j}=$ the latest finish time of activity $j$

$M_{j}=$ the quantity of selectable executing mode of activity $j$, where $m=\left\{1,2,3, \cdots, M_{j}\right\}$

$P_{j}=$ the set of precedence activities of activity $j$

$K^{\rho}=$ the set of recoverable resource type, where $\left|K^{\rho}\right|$ represents the kind of type

$X_{j t}=\left\{\begin{array}{lc}1, & \text { activity } j \text { finishes at time } t \\ 0, & \text { otherwise }\end{array}\right.$

$Y_{j t}=\left\{\begin{array}{cc}1, & \text { processing timeof activity } j \text { containstime } t \\ 0, & \text { otherwise }\end{array}\right.$

\subsection{Mathematic Equations of the Multi-Resource} Problem

The development and mathematic illustration of the multiresource project scheduling is presented as follows.

Objective function of the multi-resource problem:

$$
\operatorname{Min} Z=\sum_{t=E F_{j}}^{T} t X_{j t}+\sum_{j=1}^{J} \sum_{t=E S_{j}}^{L F_{j}} Y_{j t}
$$

The objective function, i.e. Eq. (1), is to minimize the total project completed duration, which is the sum of total completed activities durations and the total partial durations of activities having time $t$ included. The $\mathrm{T}$ value can be the sum of all different lasting duration or the project completion time under the precedence requirement and resource constrained requirement.

Constraints of the multi-resource problem are presented as the followings:

$$
\sum_{t-E F_{j}}^{L F_{j}} X_{j t}=1, j=1, \ldots, J
$$

In Eq. (2), $X_{j t}$ is an indicator variable and the value equals to one when the activity $\mathrm{j}$ is scheduled within time region $\left[E F_{j}, L F_{j}\right]$. Hence, the accumulation of $X_{j t}$ shows that the activity $j$ has to be completed within time region $\left[E F_{j}, L F_{j}\right]$. The equation represents the duration of activity $j$.

$$
\sum_{t=E F_{j}}^{L F_{j}} X_{j t}\left(t-d_{j}\right) \geq \sum_{t=E F_{i}}^{L F_{i}} t X_{i t}, j=1, \ldots, J, j \in P_{j}
$$

Eq. (3) represents the requirement of the activity sequence relationship, that is, each one activity has to be started after its precedent activity is finished.

$$
\sum_{\tau=t-d_{j}+1}^{t} Y_{j \tau} \geq d_{j} X_{j t}, \forall j, E F_{j} \leq t \leq L F_{t}
$$

In Eq. (4), it shows that if activity $j$ is completed at time $t$, where $\left(X_{j t}=1\right)$, then time $\tau \in\left\{t-d_{j}+1, \ldots, t\right\}$ must occur within the processing time of activity $j$, which means $Y_{j t}=1$ and $\tau \in\left\{t-d_{j}+1, \ldots, t\right\}$. Due to the objective is minimization, the equality of Eq. (4) is fulfilled. If $X_{j t}=0$, due to minimization, the time $\tau \in\left\{t-d_{j}+1, \ldots, t\right\}$ is not within the activity execution time duration, $Y_{j t}$ must be zero, i.e. $Y_{j t}=0$.

$$
\begin{gathered}
\sum_{j=1}^{J} r_{j k} Y_{j t} \leq R_{k}^{\rho}, \forall k \in K^{\rho}, t=1, \ldots, T \\
\text { where } \mathrm{X}_{j t}, Y_{j t} \in\{0,1\}, \forall j, E F_{j} \leq t \leq L F_{j} .
\end{gathered}
$$

Eq. (5) is used as the requirement of recoverable resources. This equation is formed to show the limit of recoverable resource. This represents that within any possible activity time $t$, where $t \in[1, T]$, the total quantity of recoverable resources usages is not allowed to exceed the preset limitation.

\subsubsection{Scheduling Scheme and Applying Ant Colony Optimization}

As discussed in the previous section, general near optimal heuristic scheduling scheme of resource constrained project scheduling problems can be two different models which include Serial Generation Scheduling Scheme (SSGS) and Parallel Generation Scheduling Scheme (PSGS). These two schemes also have two different methods, which are forward and backward methods. However, the major shortcoming of SSGS method is lacking of dynamic characteristic which the priority of activities are predetermined at the very beginning. Hence, this research mainly applies the Forward Parallel Generation Scheduling Scheme (FP) as the primary scheduling model. For the forward parallel method, among the list of activities, all the precedent activities of each one activity are located prior positions in the activities list.

Main procedure of Forward parallel method (FP), as shown in the Fig. 2., is to put in schedulable activities as early as possible when scrolling along time gradually. And at the same time point (the activity finish time point), considers multi-activity to schedule in to project under the registration of satisfying activity precedent relationship and resource restriction.

\subsubsection{Applying Ant Colony Optimization}

The main procedure is letting ants to construct a primary solution $\mathrm{X} 0$ and $\mathrm{F}(\mathrm{X} 0)$ is its goal which is the completion time of the scheduled project. After this, one renews the set of waiting activities and sequenced to schedule those activities based on transform rule. At the mean time, one also executes renewing pheromone concentration area. After all ants search for this entire generation, one uses FP method to improve for obtaining the best solution and then performing pheromone global renew. The followings show the procedures of Ant colony optimal algorithm: 
6 Huang, H. H., Huang, C. H., and Pei, W.

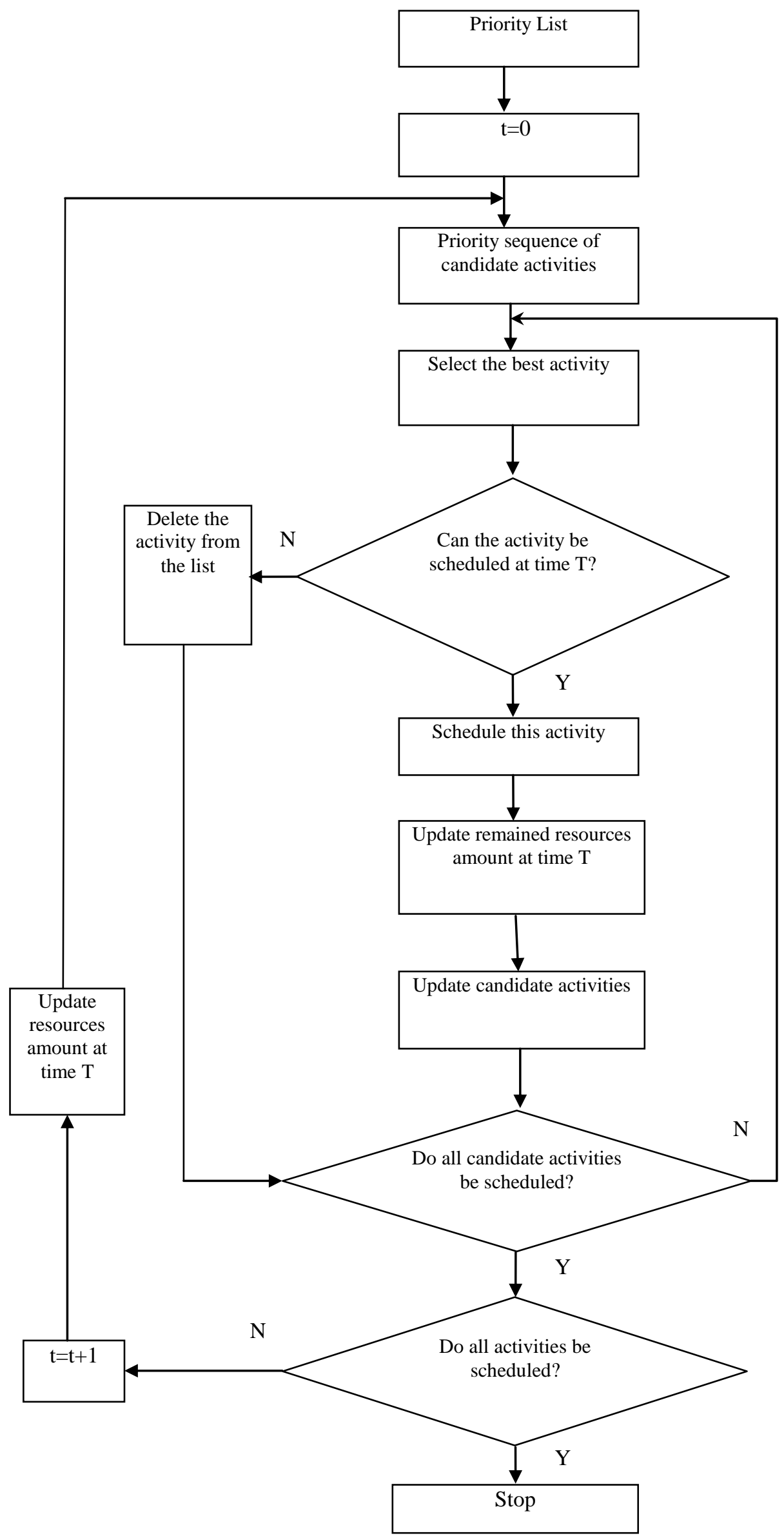

Fig. 2. Flow diagram of forward parallel generation scheduling scheme 
Step 1, setting initial values and variables:

Setting initial values and variables include number of ants, total number of generations, initial value of pheromone, pheromone variables, distance variables from activity $\mathrm{i}$ to activity $\mathrm{j}$, and pheromone residual coefficient.

Step 2, to establish each one ant's journey:

First to put all ants at the starting node (i.e. source node), and then setting the first node of all activities to be the set of selecting activities for each one ant. Then, one selects next activity according to Eq. (6). Every one ant, at the node where it stays, compares two random numbers, $q$ and $q_{0}$, which created randomly. For $q \leq q_{0}$, the transform rule is applied to select next node, which is to select the path that having high pheromone concentration and shortest distance. Here Eq. (7) is then used for this procedure. According to Eq. (7), every one ant calculates the multiplied value of quantity of pheromone and $\beta$ power of the value got from dispatching rule. Every one ant selects the maximum multiplied value form the set of selecting activities to be its next node.

On the other hand, if $q>q_{0}$, one should uses development transform probability and to select a node that never been visited and having the largest transform probability.

$$
\begin{gathered}
j=\frac{\max }{J}\left[\tau_{i l}(t)\right]^{\alpha} \times\left[\eta_{i l}\right]^{\beta} \\
P_{i l}^{k}(t)=\frac{\left[\tau_{i l}(t)\right]^{\alpha} \times\left[1 / \eta_{i l}\right]^{\beta}}{\sum_{\mathrm{u} \in \mathrm{j} \text { s(i) }}\left[\tau_{i l}(t)\right]^{\alpha} \times\left[1 / \eta_{i l}\right]^{\beta}}
\end{gathered}
$$

Step 3, the local pheromone renewal rule:

$$
\tau_{i j}(t)=\rho \times \tau(t)+\left(1-\rho \times \tau_{0}\right)
$$

Eq. (8) is a local pheromone renewal rule and the way of renewal is that once an ant walks through, it will be renewed. The purpose is to avoid all the ants go through the same path with higher pheromone and creates the block or cease moving.

Step 4, the global pheromone renewal rule:

Calculating the completed journey of each one ant, and selects the best one path among them. And then go processing the global renewal process as shown in Eq. (9). The purpose is to enhance the current best solution.

$$
\tau_{i j}(t+1)=\rho \times \tau_{i j}(t)+(1-\rho) \times \frac{1}{L_{\text {best }}}
$$

Step 5, stopping criteria:

The stopping criteria of Ant colony optimal is that when the setting numbers of scheduling solutions are fulfilled then stop.

\section{Empirical and Case Study}

In this section, examples are used to be tested and examined the feasibility and effectiveness of the proposed algorithm. In section 4.1, a single resource project case is used for further comparison and demonstration. In section 4.2 , testing cases adopted form the international test bank PSPLIB (the project scheduling problem library generated by Kolisch and Sprecher (1996)) is used for this research. There are three testing cases include $\mathrm{j} 10, \mathrm{j} 14$ and $\mathrm{j} 18$ case types with different number of activities, each activity has two mode types. In this research, simulation is written by Visual Basic 2008 and Microsoft Access. Using this program, the loading graph, or the so called Mountain Cumulated graph, can automatically be scheduled and charted. The computer execution environment is shown as the following: CPU: Intel 1.86GHz - RAM: DDR 600 3GB, HD : 1TB, OS: Windows 8.

\subsection{Case Testing: Single-Resource Project}

There are thirteen activities of this single-resource project example. Detail information of the project is given at Table 2. Initial total number of resources is 29 . This paper tends to find solution by two phases, phase 1 uses ant colony optimal algorithm to search for the shortest project completion time and draws the resources leveling figure; phase 2 changes resources requirement and to exam that is there existing delay for project or not.

For the phase 1, calculation results for same singleresource project. The Fig. 3 is the scheduling solution adopted from Kung (2005). From the figure, the shortest complete duration of project is 21 weeks. In this paper, the proposed Ant colony optimization method is applied to Kung's example for comparison and as one can see from Fig. 4 that after using Ant colony optimization and scheduled by written program for ten times, the automatically pictured best result is 20 weeks which is better than Kung's result. The total computer operating time is 45 seconds.

For phase 2, total resource number is changed into 28 units, instead of 29 units. This example is again run for ten times for analyzing, and the result is shown in Figure 5. Result from the figure shows that although total number of resources is reduced one unit from 29 units into 28 units, the shortest completion duration of project is 21 weeks which is the same as the case having 29 units. Result shows that the proposed algorithm can reduce cost, does not have to use up to 29 units, without increase any time of the same case.

Therefore, this can now be verified that the proposed algorithm and computer programming are better than the method proposed by Kung under single-resource constrained case. This research result can not only reduce the waste of resource usage and costs, but also can automatically provide the loading figure derived from resource leveling process.

\subsection{International Case Database Testing}

In this section, three international case types of RCPSP picked from PSPLIB test bank, i.e. j10, j14, and j18, are analyzed and verified. Number of activities and resources are all different for these three case types. There are twelve activities of $\mathrm{j} 10$, sixteen activities for $\mathrm{j} 14$, and twenty activities of $\mathrm{j} 18$; three cases have two different types of resources required. The basic information for the testing cases is listed in Table 3. One can observe the complexity of the testing cases. This research will apply Ant Colony Optimization (ACO) to solve the problem and compare to other algorithms in GA (Hiyassat, 2001) and SA (Bouleimen and Lecocq, 2003). We use the data of j10 as an example to process and analyze, detail information is shown in Table 4.

Owing to activities are restricted by multi-resource, when one tries to control the total amount of any one type of resources, there will be many different combinations of 
resources requirement occurred. This example case contains two different types of resources, namely resources $\mathrm{A}$ and $\mathrm{B}$. The total number of resource $\mathrm{A}$ is restricted up to 14 units and of resource B is restricted up to 10 units. The optimal project duration form test bank shown is 22 days. By using our program with ACO algorithm runs for ten generations, results are shown in Fig. 6 and Fig. 7. Here, Fig. 6 shows the result of shortest project completion duration of case j10 is 16 weeks. Fig. 7 shows the result that the longest project completion duration of case $\mathrm{j} 10$ is 24 weeks. The result of this research is from 16 weeks to 24 weeks, which is better than the result from test bank.

Next testing procedure is to run test case types, $\mathrm{j} 10, \mathrm{j}$ 14 , and $\mathrm{j} 18$ for ten times. That is, for $\mathrm{j} 10$ case type, we run ten times for 536 cases and totally are 5360 times for j10 only. Results of all cases are then compared with the best solution from PSPLIB. Table 5 shows the comparisons of deviations results. Our research results are the best solution and better than test cases.

Table 6 shows the comparison results obtained from Genetic Algorithm (GA) and Simulated Annealing (SA), which are very popular in recent years. We apply ACO, GA, and SA to run the test cases of j10, j14 and j18 from PSPLIB test bank for ten generations. Results also show that most solutions are the best by using ACO algorithm. The red blanks represent the best solutions and the pink is the second best solution. The experiment results show that Ant Colony Optimization has better capability to obtain better solution. We obtain the best results in j14 and j18 case types; and also the best solution in j10 case type which is the same best solution compared to GA algorithm result. As the number of activities of example problem increased, results also show that: 1. this research method can guarantee 100 percent obtain feasible solutions; 2 . along with increasing number of activities, the average total deviation value is better than other methods; 3 . as the computing time, the speed is also within the acceptable range.

\section{Conclusions}

This research discusses resource leveling for the multiresource constrained project scheduling problem and uses test cases from international bank to verify target and results. When multi-mode resource constrained project scheduling problem (MM-RCPSP) contains two types of resources, difficulty of obtaining feasible solutions is NPcomplete, not to mention to find the optimal solution.

This study applies the Ant Colony Optimization (ACO) algorithm to solve problems. Two phases includes single-resource and multi-resource project scheduling problems are discussed. By using algorithm to solve and to leveling resources, the computer program developed can automatically charting out directly which can provide management or project managers to make their best decision. In the phase 2 , different algorithms are included to test and to compare results with ACO algorithm used in this study. After a further more examples added for experimentation, result shows that projects with small or large scale number of activities, using ACO method is obviously better than other methods. Results also found that all the computation times for different cases are within reasonable range. This verifies that this research and method can obtain reasonable and accurate best scheduling.

Table 2. The example of the single-resource project

\begin{tabular}{cccc}
\hline Activity No. & Duration & Successor activities & Quantity of resource needed \\
\hline 1 & 3 & $2,3,4$ & 15 \\
2 & 3 & 8 & 6 \\
3 & 8 & 6,7 & 12 \\
4 & 2 & 5 & 10 \\
5 & 2 & 6 & 10 \\
6 & 5 & 10 & 12 \\
7 & 2 & 11 & 6 \\
8 & 3 & 14 & 14 \\
9 & 3 & 13 & 8 \\
10 & 2 & 13 & 10 \\
11 & 2 & 13 & 15 \\
12 & 4 & 13 & 10 \\
13 & 6 & 14 & 0 \\
14 & 0 & 0 & \\
\hline
\end{tabular}

Table 3. The basic information for the testing cases

\begin{tabular}{|c|c|c|c|}
\hline Case Type & $\mathrm{j} 10$ & $\mathrm{j} 14$ & $\mathrm{j} 18$ \\
\hline Number of activities & 12 & 16 & 20 \\
\hline Number of resource types & 2 & 2 & 2 \\
\hline $\begin{array}{c}\text { Total number of testing cases for each case } \\
\text { type }\end{array}$ & 536 & 551 & 552 \\
\hline
\end{tabular}




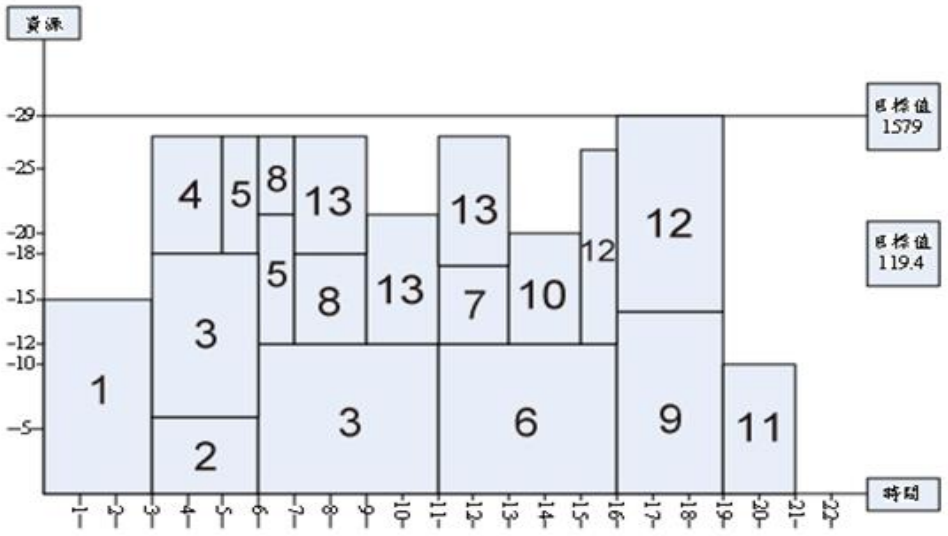

Fig. 3. Final solution of the single-resource project resource leveling example from Kung (2005) (its completion time is 21 weeks)

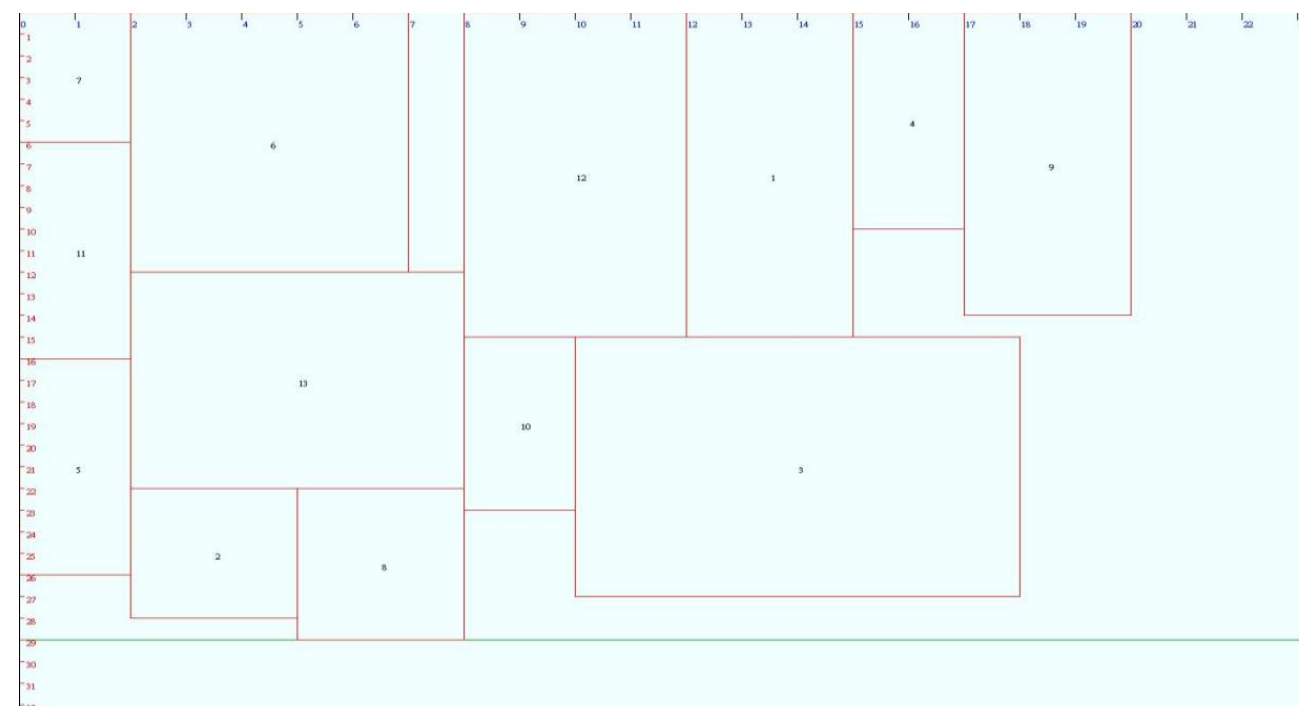

Fig. 4. Kung's example results in 20 weeks of completion time by applying Ant colony optimization

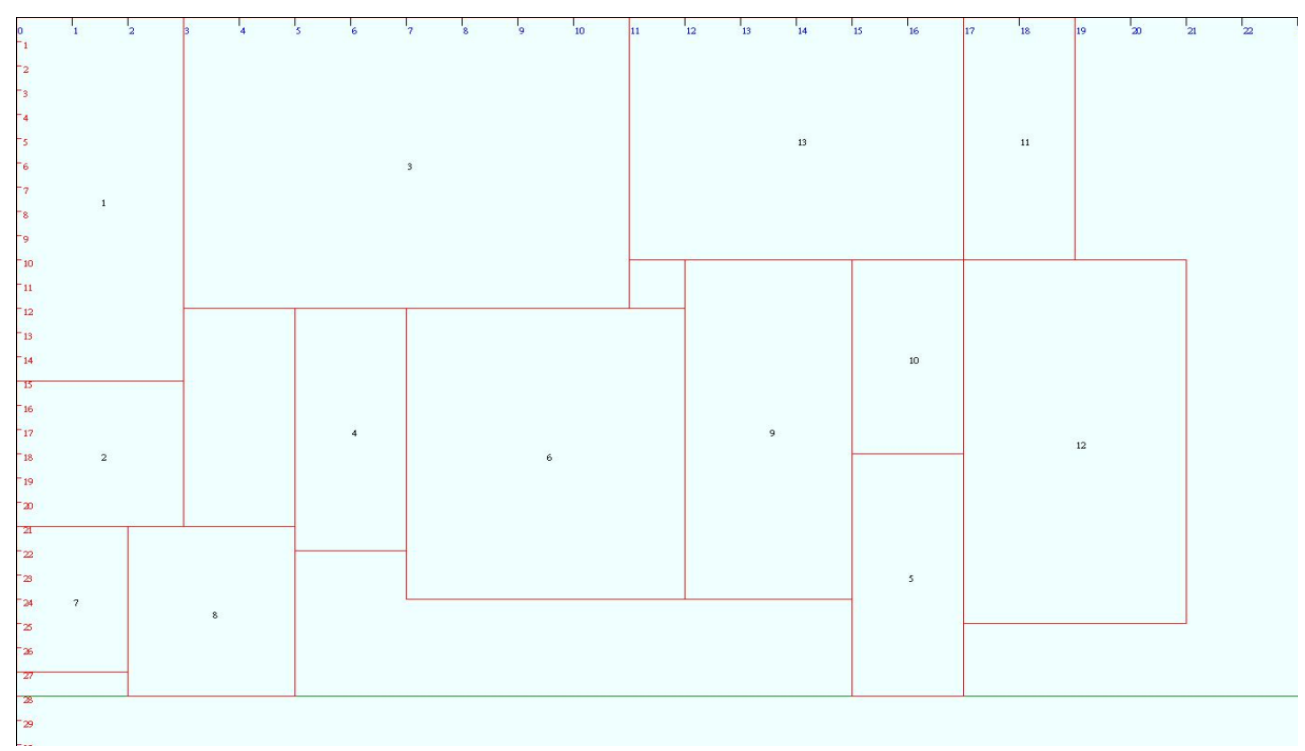

Fig. 5. The resource leveling result by reducing one unit of resource (i.e., the total resource number is changed from 29 into 28 units) 
10 Huang, H. H., Huang, C. H., and Pei, W.

Table 4. Data of the international testing case $\mathrm{j} 10$

\begin{tabular}{ccccc}
\hline Activity No. & Activity duration & Successor activities & Resource A & Resource B \\
\hline 1 & 0 & $2,3,4$ & 0 & 0 \\
2 & 2 & 10 & 0 & 8 \\
3 & 4 & 6,11 & 0 & 6 \\
4 & 5 & 5 & 4 & 0 \\
5 & 2 & $6,7,11$ & 5 & 0 \\
6 & 6 & 8,9 & 0 & 5 \\
7 & 1 & 8,9 & 5 & 0 \\
8 & 1 & 10 & 10 & 0 \\
9 & 1 & 12 & 0 & 8 \\
10 & 8 & 12 & 0 & 3 \\
11 & 1 & 12 & 6 & 0 \\
12 & 0 & 0 & 0 & 0 \\
\hline
\end{tabular}

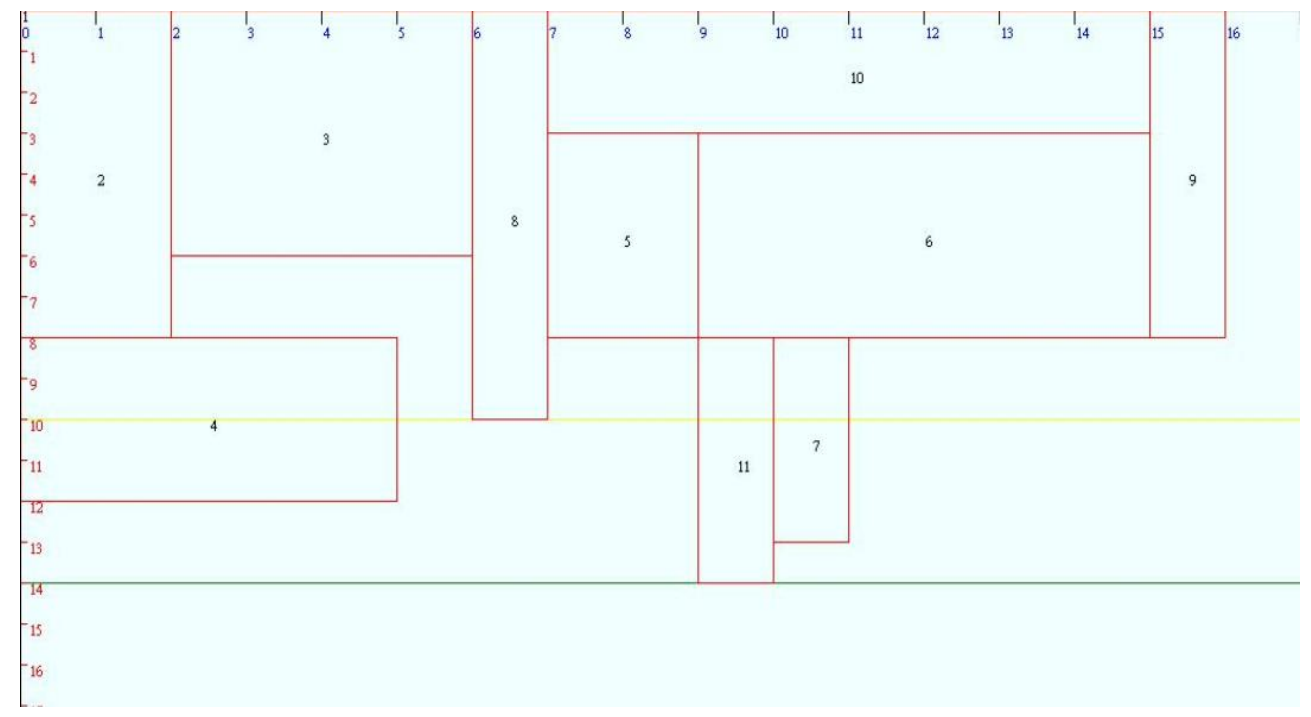

Fig. 6. The optimal project completion duration of case $\mathrm{j} 10$ (which is 16 weeks)

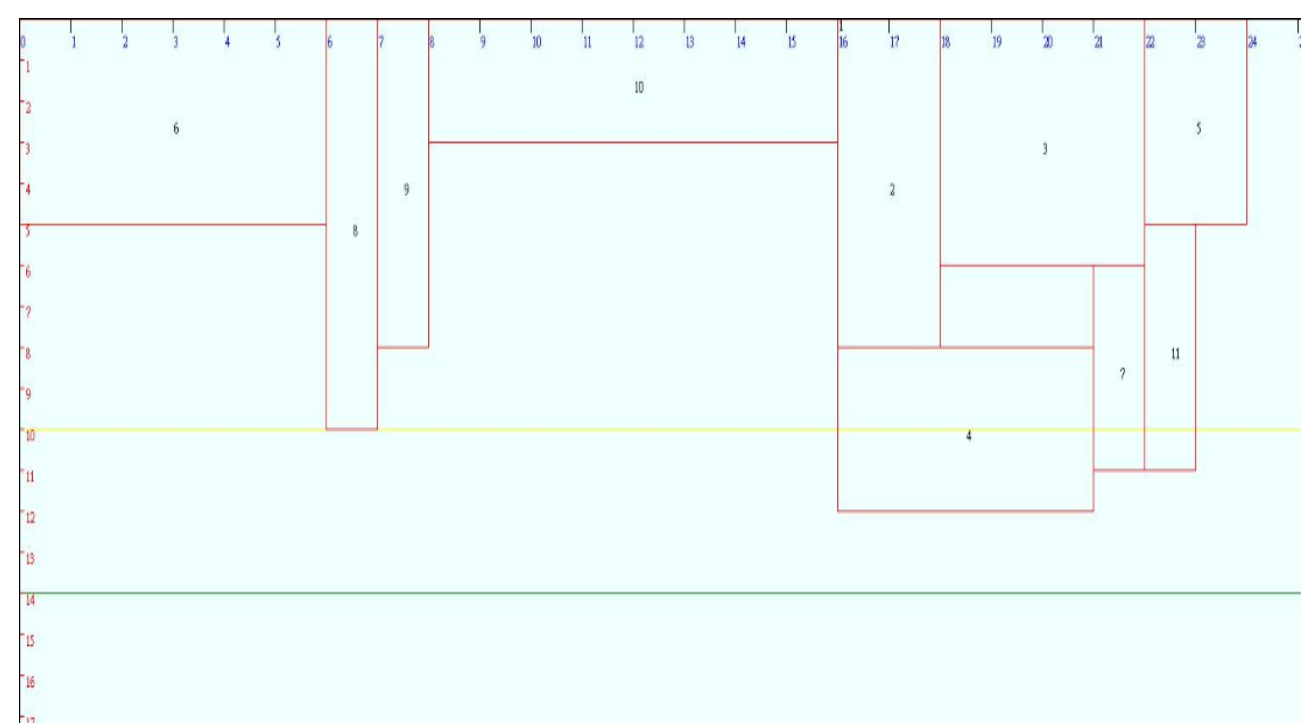

Fig. 7. The longest project completion duration of case j10 (which is 24 weeks) 
Table 5. The comparisons of deviations with best solutions of test bank

\begin{tabular}{cccccc}
\hline Case & $\begin{array}{c}\text { Min. deviation } \\
\text { value }\end{array}$ & $\begin{array}{c}\text { Average deviation } \\
\text { value }\end{array}$ & $\begin{array}{c}\text { Max. deviation } \\
\text { value }\end{array}$ & $\begin{array}{c}\text { Percentage of } \\
\text { obtaining feasible } \\
\text { solution }\end{array}$ & $\begin{array}{c}\text { Average computing } \\
\text { time (sec) }\end{array}$ \\
\hline $\mathrm{j} 10$ & 0.058 & 0.285 & 1.139 & $100 \%$ & 15.725 \\
\hline $\mathrm{j} 14$ & 0.312 & 0.856 & 1.313 & $100 \%$ & 54.707 \\
\hline $\mathrm{j} 18$ & 0.723 & 1.4 & 3.302 & $100 \%$ & 92.808 \\
\hline
\end{tabular}

Table 6. The comparisons of deviation values of cases $\mathrm{j} 10 \sim \mathrm{j} 18$ from international project cases library (PSPLIB) with GA and SA algorithms

\begin{tabular}{cccc}
\hline Case Type & $\mathrm{j} 10$ & $\mathrm{j} 14$ & $\mathrm{j} 18$ \\
\hline ACO (this research) & 0.24 & 0.956 & 1.4 \\
\hline GA (2001) & 0.24 & 1 & 1.43 \\
\hline SA (2003) & 1.16 & 2.6 & 5.52 \\
\hline
\end{tabular}

\section{References}

Alcaraz, J., Maroto, C., Ruiz, R. (2003). Solving the multi-mode resource-constrained project scheduling problem with genetic algorithms. Journal of Operational Research Society, 54, 614-626.

Antill, J. M. and Woodhead, R. W. (1990). Critical Path Methods in Construction Practice, 4th ed., Wiley Interscience.

Bell, C. E. and Han, J. (1991). A New Heuristic solution method in resource-constrained project scheduling. Naval Research Logistics, 38, 315-331.

Boctor, F. F. (1998). Some efficient multi-heuristic procedures for resource-constrained project scheduling. European Journal of Operational Research, 49, 3-13.

Bouleimen, K. and Lecocq, H. (2003). A new efficient simulated annealing algorithm for the resourceconstrained project scheduling problem and its multiple mode version. European Journal of Operational Research, 149, 268-281.

Davis, E. W. and Patterson, J. H. (1975). A comparison of heuristic and optimum solutions in resourceconstrained project scheduling. Management Science, 21, 944-955.

Dorigo, M. and Gambardella, L. M. (1997) Ant colony system: A cooperative learning approach to the traveling salesman problem. IEEE Transactions on Evolutionary Computation, 1, 53-66.

Gen, M. and Cheng, R. (1997), Genetic Algorithms and Engineering Design, New York: Wiley.

Gido, J. and Clements, J. P. (2008). Successful Project Management, South-Western College Publishing.

Hartmann, S. and Drexl, A. (2001). Project scheduling with multiple modes: A Genetic algorithm, Annals of Operations Research, 102, 111-135.

Hiyassat, M. A. S. (2000). Modification of minimum moment approach in resource leveling. Journal of Construction Engineering and Management, ASCE, 126(4), 278-284.

Hiyassat, M. A. S. (2001). Applying modified minimum moment method to multiple resource leveling.
Journal of Construction Engineering and Management, ASCE, 127, 3, 192-198.

Huang, H. H., Shiu, J. C., Chen, T. L. (2011). The Project Scheduling and Decision Mechanism Based on the Multi-Resource Leveling. 2011 Iternational Conference on Engineering, Project and Production Management, EPPM 2011, National University of Singapore, Singapore.

Kelley, J. E. (1963). The Critical Path Method;Resources Planning and Scheduling, Prentice-Hall, Englewood Cliffs, New Jersey.

Kolisch, R. (1996). Serial and parallel resourceconstrained project scheduling methods revisited: Theory and computation. European Journal of Operational Research, 90, 320-333.

Kolisch, R. and Sprecher, A. (1996). PSPLIB-A project scheduling problem library. European Journal of Operational Research, 96, 205-216.

Kung, E. Y., (2005). A Study on Multi-resource Leveling Scheduling Optimization. Master Thesis, National Pingtung University of Science and Technology, Pingtung, Taiwan.

Leu, S .S. and Yang, C. H. (1999). GA-Based multicriteria optimal model for construction scheduling. $J$. Constr. Eng. and Mgmt., ASCE, 125(6), 420-427.

Leu, S. S., Yang, C. H., Huang, J. C. (2000). Resource Leveling in Construction by Genetic Algorithmbased Optimization and Its Decision Support System Application. Automation in Construction, 10, $27-41$.

Mattila, K. G. and Abraham, D. M. (1998) Resource Leveling of Linear Schedules using Integer Linear Programming. Journal of Construction Engineering and Management, ASCE, 124(3), 232-244.

Merkle, D., Middendorf, M., Schmeck, H. (2002). Ant colony optimization for resource-constrained project scheduling. IEEE Transactions on Evolutionary Computation, 6, 333-346.

Mika, M., Waligora, G., Weglarz, J. (2005). Simulated annealing and tabu search for multi-mode resourceconstrained project scheduling with positive discounted cash flows and different payment models. 
European Journal of Operational Research, 164, 639-668.

Mueller-Merbach, H. (1967). Experience with methods for resource scheduling in CPM networks. INTERNET Conference, Vienna.

Neumannn, K. and Zimmermann, J. (1999). Theory and methodology resource leveling for project with schedule-dependent time windows. European Journal of Operational Research, 117, 591-605.

Nguyen, Q. T. and Chua, D. K. H. (2014). Criticality of Schedule Constraints - Classification and Identification for Project Management. Journal of Engineering, Project, and Production Management, 4(1), 17-25.

Son, J. and Skiboniewski, M. J. (1999). Multi-heuristic approach for resource leveling problem in construction engineering hybrid approach. Journal of Construction Engineering and Management, 125(1), 23-31,.

Sprecher, A. and Drexl, A. (1998). Multi-mode resourceconstrained project scheduling by a simple, general and powerful sequencing algorithm. European Journal of Operational Research, 107, 431-450.

Valls, V., Ballestin, F., Quintanilla, S. (2005). Justification and RCPSP: a technique that pays. European Journal of Operation Research, 165, 375-386.

Wiest, J. D, (1967). A heuristic model for scheduling large projects with limited resources. Management Science, $13,359-377$.

Liu, Z. and Hongwei, W. (2006). Heuristic algorithm for RCPSP with the objective of minimizing activities cost. Journal of Systems Engineering and Electronics, 96-102.

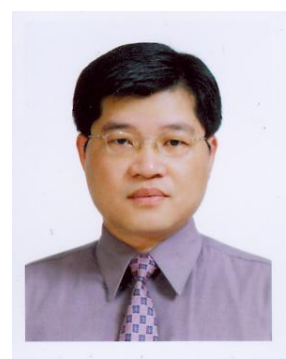

Dr. Hsiang-Hsi Huang is now a Professor of Department of Industrial Management and Vice Dean of College of Management of National Pingtung University of Science and Technology. Professor Huang is currently serving as an Editor-in-Chief of TPMA Journal of Project Management, the Director for the International EPPM Association, the Director for the Society of Lean Enterprise Sys of Taiwan. Dr. Huang is also a Certified Lecturer and DELTA Evaluator of Taiwan Project Management Association (TPMA). Dr. Huang was also a visiting scholar at Automation and Robotics Research Institute (ARRI) of the University of Texas at Arlington (UTA) in USA from July 2009 to June 2010. Professor Huang is now also working as an Director of the Society of Lean Enterprise Systems of Taiwan. He received his Ph.D. degree in Industrial Engineering in 1995 at the University of Texas at Arlington in USA. Dr. Huang served as chairman for his Department in 2003. He also received the Best Research award in 1996 from the National Science Council in TAIWAN. In 2006, Dr. Huang received the 2006 Medal of Management Award for Young Educator awarded by CMA (Chinese Management Association). Dr. Huang had served as the Convener on south Taiwan working committee of Chinese Institute of Industrial Engineers (CIIE) for four years from

2004 to 2008. Dr. Huang's research areas of interest include intelligent controls of automated manufacturing systems, facilities planning, project management, and supply chain management.

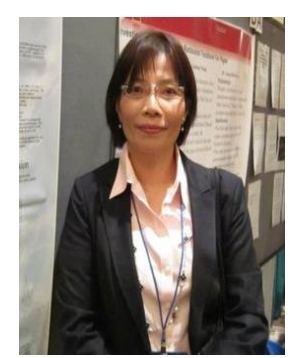

Dr. Ching-Hsu Huang earned her Ph.D. in 2003 from Penn State University, USA. She has gotten many grants from National Science Council at Taiwan which is prestigious symbol in terms of academic achievement. She also has published many papers in peer reviewed social scientific research journals in Taiwan or international countries. Dr. Huang is the secretary in Asia Pacific Council of Hotel, Restaurant and Institutional Education (APacCHRIE), a federation of the international CHRIE.

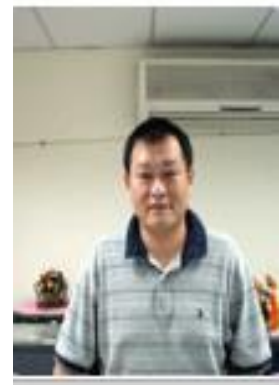

management.
Dr. Wen Pei is now an Associate Professor of Department of Business Administration of Chung Hua University, Taiwan. He earned his Ph.D. degree in Industrial Engineering at the University of Texas at Arlington in USA. Dr. Pei's research areas of interest include enterprise strategy planning, ant colony algorithm, and fuzzy 